\title{
Origen del proceso emigratorio de la mujer filipina a Cataluña
}

\author{
Natalia Ribas \\ Instirur d'Estudis Catalans. Secció de Filosofia i Ciències Socials \\ Carme, 47. 08001 Barcelona. Spain
}

\section{Resumen}

El articulo expone las conclusiones de un trabajo de campo realizado en Filipinas, con el objetivo de analizar las condiciones de origen de la emigración de las mujeres filipinas a Cataluña. El estudio cualitarivo pretende así poder conocer el proceso migratorio en toda su totalidad.

El análisis precisa de un enclave contextual internacional y nacional para entender el fenómeno migratorio, producto de una crisis socioeconómica que ha lievado a la mujer filipina a emigrar, ante la estrechez del mercado laboral y las necesidades familiares. Occidente ofrece la postbilidad de realizar el trabajo doméstico a cambio de altos salarios, se elegirá pues uno de los países en base a la flexibilidad fronteriza, el mercado de rrabajo y la estereotipación de los estilos de vida de los paises de destino.

Palabras clave: emigración, inmigración, mujer filipina.

\section{Abstract. Origen of the migratory process of filipina migrant in Catalonia}

This article shows the conclusions of a field work carried out in the Philippines with the purpose of analyzing the conditions of the emigratory origen of Filipines migrant in Catalonia. The qualitative research represents an atternpt of knowing the whole of the migratory process.

The analysis precises an international and domestic context to unable the understanding of the migratory phemomena, product of the socio-economic crisis, which has pushed Filipines migrant to emigrate abroad, considering the limitations of the labour market and the family needs.

The West offers jobs as domestic helpers and high wages, therefore, the countries will be choosen according to the borders' flexibility, labour market and the stereotypes of the way of life in the countries of destiny.

Key words: emigration, immigration, philippine woman.

\section{Sumario}

1. El estudio del proceso migratorio de los flujos filipinos a Cataluña precisa de un enclave contextual, internacional y nacional 
2. A pesar del alto status de la mujer filipina en la sociedad - asociado a su historia precolonial-, la crisis ha incidido especialmente en su situación socioeconómica

3. La emigración filipina a Cataluńa responde al papel de la mujer como estratega familiar

4. Como en todo modelo migratorio, se requiere una cierta selección de la migrante

5. Ante la falta de libre elección, el salario occidental es la única opción, y el traba- jo doméstico la única oferta

6. La elección del país comporta un análisis de la flexibilidad fronteriza, del mercado de trabajo y de la estereotipacion de los estilos de vida de los países de destino

7. El concepto de integración se enraiza en una realidad interactiva multiforme. A cada tipo de interacción entre sociedades le corresponde una integración diference, lo cual se maniftesta en las diferentes imágenes y estereotipos de los países de destino

En los estudios actuales sobre inmigración en Cataluña se destaca la existencia de un desconocimiento del "otro", debido a la falta de tradición inmigratoria extracomunitaria, a la vez que a la falta de un marco educativo multicultural. Este escrito pretende analizar la situación desde la sociedad de partida para poder conocer el proceso migratorio en su totalidad.

Al intentar dar respuesta a las necesidades que implica la integración, se plantea el estudio de las condiciones de origen de la población inmigrante, en este caso, la colonia filipina, peculiarizada por su alto grado de feminización $y$ alto nivel de estudios de las migrantes en relación con otros colectivos ${ }^{1}$. Partimos de la cuestión de cómo abordar el tema de la integración haciendo hincapié, por un lado, en el peso cuantitativo de los flujos migratorios de mujeres en la Europa de los años ochenta y noventa ${ }^{2}$ y, por el otro, en el peso del papel integrador de las mujeres, tanto en las sociedades de origen como en las de destino.

En este artículo quiero exponer algunas de la conclusiones de un trabajo de campo realizado en Filipinas durante los meses de agosto y septiembre de $1993^{3}$, financiado por el Institut d'Estudis Catalans.

1. Ver: Dirección General de Emigración (1992). Anuario de Migraciones 1992. Madrid: Ministerio de Trabajo y Seguridad Social. Dirección General de Emigración, 1992.

Amaqui, R. (1992). Country Report on the situation of Filipinas in Spain. Barcelona: Documento interno de la Asociacion Amistad.

2. Ver, por ejemplo, los escritos de Morokvasic, M. (1992). New dimensions of migration in Europe and gender. Barcelona: UNESCO. International Seminar. Migrant Women in the 1990s: Cross-cultural perspectives on new trends and issues.

Ver también los estudios que se centran en la emigración de la mujer fllipina: MedelAñonuevo, C. (1992). Femenist reflections on the international migration of women. Asia and Pacific Women's sudies journal. Institure of Women's Studies. Number 1.

3. El trabajo de campo consistió en 31 entrevistas en profundidad a mujeres que tenían alguna relación de parentesco con las mujeres emigradas a Catalunya, además de entrevistas a ONG, a funcionarios del gobierno y a agencias de reclutamiento de mano de obra en el extranjero. 


\section{El estudio del proceso migratorio de los flujos filipinos a Cataluña precisa de un enclave contextual, internacional y nacional}

Se inserta, en primer lugar, en un análisis internacional caracterizado por los contextos siguientes:

a) el contexto de los desequilibrios del sur -especialmente en relación al género- respecto al norte, como producro de una historia colonial (ejemplificada primordialmente por el papel de la España colonial, juntamente con la relación de dependencia de Filipinas en Estados Unidos, en Japón y en los países petrolíferos del Golfo, y

b) en el contexto regional del sudeste asiático.

En el análisis internacional de la mano de obra filipina se distinguen dos modelos: el contractual, característico de los países del Golfo, y la emigración filipina no contractual en el marco de la inmigración de la Comunidad Europea (sobresalen España e Italia como los países con mayor concentración de filipinos en Europa) ${ }^{4}$.

En segundo lugar, a nivel nacional, el estudio se inserta en las causas de la crisis (económica, política, financiera y de desastres naturales) de un pafs (densamente poblado y organizado en base a una estructura semi-feudal) que ha fundado las bases para un sentimiento generalizado de frustración social en el pueblo.

La solución adoptada por el gobierno filipino $-y$ por otros gobiernos como el español en los años sesenta o el marroquí y el caboverdiano en el momento actual - basada en la correspondencia entre desarrollo y emigracion, no ha resuelto las causas primeras de la crisis: las estructurales.

EI Estado se ha establecido como el mediador de las relaciones entre el capital y la fuerza de trabajo migrante.

El estudio se delimitó a zonas foco de la emigración a Caralunya: Batangas, Ilocos norte, Ilocos sur, Metro Manila (codas en Luzón) e Iloilo.

La colaboración de la Embajada Española en Filipinas, de la profesora Maureen Orara de "University of the Philippines", de Nati Palanca, Manuel Zarate y de miembros de OWWA (Overseas Workers Welfare Administration) en Manila, Baguio City y muy especialmenre en Iloilo, fueron indispensables para la realizacion del rrabajo en Filipinas.

4. Gran parte del material analizado para el análisis de la distribución de los emigrantes filipinos en el mundo corresponde a las estadísticas oficiales siguientes (POEA. Philippine Overseas Employment Agency):

- POEA (1988). The Official Publication of the Philippine Overseas Employment Administration. POEA News.

- POEA (1989). Matrix on entry regulations and market barrier in emerging labor markets. Overseas Employment Info Series. Vo1. 2, núm. 3, diciembre 1989.

- POEA (1990). Overseas Employment Info Servicies. Vol. 3, núm. 2, agosro-sepciembre 1990 .

- POEA $(1990,1991,1992)$. Deployed Landbase contract workers by country of destination. 1990, 1991 i 1992. POEA Statistics. Policies and Programs Division. Planning Branch. 
Lo que en un primer momento fue una medida temporal -iniciada en los años setenta para estabilizar la balanza de pagos a través de la acción gubernamental dirigida a controlar las políticas de mano de obra, su gestión y su reclutamiento - se ha convertido en una especificidad del sistema.

La crítica a la formula gubernamental desde la izquierda filipina, las $O N G^{5}$ $y$ los estudiosos ${ }^{6}$, se centra en los fracasos de la orientación gubernamental por el hecho de:

a) haberse guiado únicamente por las políticas macroeconómicas en detrimento de la situación de pobreza y desocupación laboral del país,

b) no haber tenido presente el hecho de que la masiva salida de población emigrada -en su mayoría ocupada - no ha solventado la saturación del mercado de trabajo (y en tanto que población cualificada, ha servido solamente a los intereses de los países desarrollados),

c) haber puesto en juego la udignidad del país" a partir de la exportación masiva de trabajadoras domésticas y entertainers ${ }^{7}$ y

d) no haber previsto los problemas de la integración socio-económica de los emigrantes retornados.

Los discursos sobre la emigración se dejan también entrever en las entrevistas: la vertiente crítica transmitida por las entrevistadas, miembros de OWWA (Overseas Workers Welfare Administration), y la vertiente conservadora (transmitida por una "mestiza hacendera" y por una ex-gestora de una agencia de reclutamiento de emigrantes).

Las primeras, analizan la situación en base a la estructura feudal de la sociedad y critican al gobierno por su "trabajo de parches" (los parches como sinónimo de medidas tomadas en situaciones de conflicto al prohibir temporalmente las contrataciones al extranjero). Critican también:

a) la falta de orientación de pre-salida, lo que explica que en los proyectos de los migrantes se consideren las necesidades inmediatas pero no los problemas sociales que pueda ocasionar la estancia en el extranjero,

b) las cuotas desorbitantes de las agencias —unas 20.000 ptas. de cuotas- ${ }^{8}$,

5. Postura ejemplificada sobre todo por la labor tlevada a cabo por Kanlugan, ONG centrada en la defensa de los derechos, la dignidad y el bienestar de los trabajadores emigrantes filipinos, de casos legales, de igualdad sexual y desarrollo nacional.

6. Postura ilustrada en los textos de Abella, M. (1982). Intemational migration and development. Philippine Labor Migration. Impact and Policy. Quezon City: Edited by Graziano Battistella and Anthony Paganoni, Scalabrini Migration Center.

7. Utilizamos el vocablo entertainer, en inglés, ya que en la bibliografía utilizada se refiere invariablemente a los artistas y a las prostituras. Ver: Kanlugan (1991). Migration and Trafficking in Women. Effects of the Economic Crisis on Filipino Women. German Protestant Church Day, Herne, 7 de junio de 1991.

$\mathrm{Y}$ también en Report of the European working Conference against trafficking of women. Amsterdam, 4 y 5 de julio de 1991.

8. La figura del prestamista de dinero, el rico del pueblo, ha sido uno de los comentarios más frecuentes en las entrevistas realizadas en el ámbito rural; los campesinos venden todas sus perrenencias para poder salir del país. 
c) el reclutamiento a través de agencias ilegales y

d) la situación en el Golfo Pérsico, desde el momento en que se da una percepción positiva de la emigración a Estados Unidos y a Europa, y una percepción negativa del Golfo, donde piensan que la mujer se encuentra todavía en un sistema esclavista.

El segundo grupo (herederos de la legitimación del poder colonial) representan la vertiente conservadora. Los hacenderos mestizos seleccionan el personal del servicio doméstico para el mercado extranjero a partir de una serie de criterios: el estado civil - soltera - de bajo nivel educativo y a partir de la actitud sumisa de la mujer en las zonas rurales como cualidades potenciales de la empleada doméstica. Para ellas, España es el destino ideal de las mujeres filipinas, por ser España parte de la cultura filipina?.

La relación de la "hacendera» (ama) con la trabajadora, equivale a la estereotipada relación paternalismo-sumisión (equiparable a la relación entre mujer inmigrante-burguesía catalana).

\section{A pesar del alto status de la mujer filipina en la sociedad —asociado} a su historia precolonial- ${ }^{10}$, la crisis ha incidido especialmente en su situación socioeconómica

Teniendo presente el nivel educativo de la mujer, vemos, por un lado, como las tasas de alfabetización femenina son muy altas, así como también el número de licenciadas ${ }^{11}$. Filipinas cuenta con los niveles educativos más aitos del sudeste asiático y presenta incluso menos contraste que España en la diferencia entre las tasas de alfabetización por sexos (ídem). El sentimiento de crisis se acentúa entre las jóvenes licenciadas; ante un mercado de trabajo que no puede absorber el gran número de maestras, enfermeras, médicos, ingenieras, etc., las jóvenes preparan sus currículums pensando en la emigración.

El contexto de realización de las entrevistas es predominantemente rural. El bambú, la madera y, en tercer lugar, el hormigón, simbolizan la escala cualitativa de las condiciones de la vivienda; los electrodomésticos, la comida enlatada, el alcohol de importación, los diplomas y las fotos de los familiares

9. La trayecroria de la emigración filipina corresponde en nuestro estudio a la emigración de mujeres filipinas a Cacalunya en los años ochenta. En contraposición al modelo anterior (años sesenta y setenta, excepto en el caso de la emigración con propósitos educativos de las hijas de las familias mestizas), las emigrantes, parientes de nuestras entrevistadas, tienen un nivel de estudios mucho más alro - -un gran porceñaje son universitarias - y utilizan otros mecanismos de salida alternativos no asociados al antiguo modelo hacendero, es decir utilizan la salida independiente con visado de turista o través de agencias legales e ilegales.

10. Ver Mananzan, M.J. (1991). The Filipino Women: Before and After the Spanish Conquest of the Philippines. Manila: Essays on Women. Women's Sutdies Seties 1. Instizure of Women Studies.

11. Naciones Unidas (1991). Compendium of Social Statistics and Indicators. 1922. New York: Unired Narions. 
en el extranjero son los símbolos que denotan los vínculos con un pariente emigrado.

Es entre los sectores en crisis - la pesca y la agricultura-, y entre los trabajadores más afectados por la crisis - Ios de "cuellos azules"-, donde identificamos las regiones foco de la emigración, principalmente en las zonas rurales.

En el campo, el sistema de división sexual del trabajo se concibe dentro de la estructura familiar (hay trabajos específicos pero integrados dentro de las redes de solidaridad familiar): el hombre sobrevive del trabajo de las tierras y de la pesca (combinándolo con el transporte de trycicles y jeepneys), y la mujer, comercializa - con escasos beneficios- los productos.

Los bajos ingresos que obtienen de los propios negocios (carinderia, sari-sari, artesanía, venta ambulante y puestos de los mercados municipales). Las ínfimas retribuciones, en desnivel con el alto coste de vida, la falta de condiciones de trabajo aceptables (desregularización de los horarios) y la discriminación de la mujer son los obstáculos a la integración económica. La vida laboral incluye a la mujer como niña y como anciana (la niña piensa en cuando emigrará y la anciana en haber podido tener la oportunidad de emigrar).

En contraste con la calidad de vida (en términos ecológicos) de la zona rural, los suburbios manilenses encarnan las pésimas condiciones de vida de muchos pobres de las ciudades del Tercer Mundo (squats y barracas, suciedad, ineficiencia del sistema de alcantarillado, inundaciones constantes de las calles, inseguridad ciudadana, población armada, etc.).

En la ciudad, el clima de insatisfacción laboral se añade a la emigración como una presión más a las fuerzas push.

La receta frustración económica-emigración es la traducción a los altos precios de los productos, a unos salarios muy bajos, a una malas condiciones de trabajo y a la discriminación de la mujer en el mercado de trabajo (además, la doble jornada intensifica las presiones sobre ella). Normalmente son las mujeres con más estudios y con más concienciación social las que hacen referencia a la discriminación.

\section{La emigración filipina a Cataluña responde al papel de la mujer como estratega familiar}

La respuesta de la mujer a la crisis se plasma en: la feminización del éxodo rural (como ocurre también con las emigrantes a Cataluña, procedentes de la emigración ilocana a Metro Manila) y en la feminización de la exportación de mano de obra al extranjero.

Con la emigración se roma una actitud: balahan, siempre hay una esperanza, incluso en las peores situaciones, «en el extranjero Dios se hará cargo de mi situaciónn.

La tradición migratoria del país y el involucramiento de la emigración en todos los aspectos de la sociedad (desde el gobierno hasta todo tipo de agencias de reclutamiento, agencias de viajes, bancos, transportistas, gestores, copiste- 
rías ambulantes, etc.) ha provocado la llamada "mentalidad de migracion" en la población.

A pesar de que la mayor parte de la población migrante femenina sea soltera, examinaremos las estrategias de la mujer casada y con hijos, porque son las que se han definido más claramente en el análisis de contenidos a la hora de considerar las razones de la emigración. De todas formas, las estrategias suelen ser similares en cuanto a que los objetivos se marcan desde un prisma familiar, desde el rol de la hija mayor como ayuda familiar o desde otras formas de apoyo a la familia extensa.

Las causas económicas inmediaras son: la alimentación y la educación de los niños de la familia, como estrategias de supervivencia (contrastando con las estrategias de competencia características de Occidente). Las causas secundarias son: mayores posibilidades de nivel de consumo (a veces esta causa puede pasar a ser una causa inmediata) y las ansias de viajar.

Las causas inmediatas afectan a la autosuficiencia tradicional de la familia extensa, desintegrada ante la crisis. En una sociedad sin estado de bienestar la mujer es, frecuentemente, la encargada de lievar a cabo el proyecto emigratorio, debe soportar las demandas familiares (hacer que las presiones económicas sean más livianas y crear un proyecto futuro de estabilidad, exclusivamente económico-familiar, bien fuera o dentro de Fillipinas).

La idea de armonía familiar es una meta constante en la mujer filipina, sin embargo, debe señalarse que en ella existen unos intereses ordenados jerárquicamente; para ella lo primero son los hijos, se entiende pues que el rol de madre y el sacrificio maternal sean los motores de la emigración. Ahora bien, no se descartan otros objetivos como son la ayuda a otros miembros familiares, o la emigración como un acto de autonomía.

El proyecto responde a tres objetivos:

a) A corto plazo, la supervivencia - alimentación-.

b) A medio plazo, la educación de los hijos.

c) A largo plazo, la elevación de status y el posicionamiento social. El objetivo a largo plazo se entiende a partir de la idea de futuro, un futuro en el que se conseguirá la estabilidad familiar que se propone la mujer filipina a través del sacrificio como madre y a través de una ética del trabajo basada en el ahorro para la furura vida terrenal (la de sus hijos y la suya propia e, incluso, la del resto de la familia extensa).

El retorno se sustenta como idea, pero normalmente no como un proyecto organizado. Por lo general, el retorno depende de las circunstancias económicas de Filipinas y de los frenos a la movilidad ocupacional en el país de destino.

Respecto a las causas secundarias, podríamos exponer múltiples de ellas, no obstante, se suelen sintetizar en un cambio de estilo de vida. Para la clase trabajadora filipina de "cuello azul", la aspiración es llegar a ser "cuellos blancos" y poder permitirse el estilo de vida de los "cuellos blancos occidentales". Como 
en muchos otros países del Tercer Mundo, la distancia entre ricos y pobres se plasma en las diferentes oportunidades para poder aspirar a un estilo de vida occidental. Para los pobres, el sueño se puede hacer realidad al emigrar a un país occidental, donde saben que la riqueza está repartida de una forma más homogénea.

Al mismo tiempo que se da una disparidad abismal en las rentas per cápita españolas y filipinas, se da también una gran disparidad entre los gastos de consumo (analizando por ejemplo el consumo de gasolina); las pautas de consumo ejercen una presión, pull, a la emigración (Fuente: Naciones Unidas, 1991).

Uno de los resultados más alarmantes de la investigación ha sido el constatar el sacrificio de la separación familiar durante años para conseguir los objetivos de la emigración: la emigración de mujeres casadas con hijos pequeños y la separación de la pareja incluso durante diez y doce años. Los niños estudian en Filipinas, al cuidado del padre, de los abuelos o de otros miembros de la familia, mientras la mujer trabaja en Cataluña ${ }^{12}$.

El modelo europeo de emigración filipina (la emigración a los pafses del Golfo Pérsico es temporal) se caracteriza por la reunificación familiar. Cuando la primera emigrante consigue ahorrar el dinero suficiente y tiene el conocimiento suficiente sobre el funcionamiento de la reunificación familiar, atrae a los demás familiares, instaurando a largo plazo colonias filipinas originadas en base a agrupaciones de familias extensas.

Un gran número de entrevistadas quiere emigrar para reunirse con la familia y utilizan la vía de la reunificación a partir de peticiones realizadas desde España (el periodo del estudio de campo coincidió con el período de reunificación familiar en España).

Para un proyecto tan nuevo para la mujer como puede ser el vivir en un pafs lejano y diferente - considerando que las entrevistadas no han salido nunca del país--, la cadena familiar ofrece el contexto de apoyo y dinero para la seguridad del individuo, y la casa del patrón viene a simbolizar la seguridad que ofrece su vivienda en un nuevo entorno.

Debe señalarse que la reunificación familiar no se limita a un solo país, la familia puede estar disgregada por diferentes países, en pequeños grupos familiares. Aparte de Cataluña y de otras partes de España, la mayoría de las entrevistadas tienen familiares en países extranjeros: Estados Unidos, Canadá, Hong Kong, Arabia Saudita y en algunos países europeos. Las conexiones principa-

12. En cuanto a la separación de la pareja por períodos tan largos de riempo, se comprende desde la perspectiva de que la emigración equivale a un compromiso con la pareja para un proyecro familiar.

La separación del marido puede deberse, por una parte, al renunciamiento de la vida conjunta en aras de conseguir el sustento familiar, pero, por la orra, se dan casos que sugieren una separación no oficial de la pareja, teniendo en cuenta que en Filipinas el matrimonio es indisoluble.

En muchos casos, cuando se da la separación familiar, la mujer casada que vive en Caraluña y que tiene los hijos pequeños en Filipinas, pese a haber estado fuera durante años, retorna con los hijos o bien se los lleva a través de la reunificación familiar. 
les de España con el resto de Europa son con Italia, por ser el país con mayor número de emigrantes filipinos en Europa.

\section{Como en todo modelo migratorio, se requiere una cierta selección de la migrante}

En el estudio cuantitativo se denota una opinión generalizada en torno a que es más fácil que emigre la mujer que el hombre, a causa de:

a) la oferta de trabajo en el extranjero, por ser el servicio doméstico un trabajo típicamente femenino $y$

b) a las cualidades atribuidas a las mujeres filipinas: dureza, coraje, ética en el trabajo (al mismo tiempo que recae sobre ella el papel de sacrificadora familiar).

En el proceso de selección de la migrante se criba primeramente en base al nivel de estudios; prefiriendo las mujeres licenciadas a causa de las prioridades marcadas por las familias y por las agencias (lo que puede incidir en que la emigración ilegal no sea tan cualificada como la contractual), y a partir de unos determinados ingresos económicos.

En el estudio cualitativo se corrobora la idea de que la mujer filipina tiene un nivel de estudios más alto que el hombre. Podemos confirmar la hipótesis de que las mujeres con menos estudios realizan un tipo de trabajo más tradicional. Ambas variables:

a) el nivel de estudios, más alto respecto al hombre e incluso más alto respecto a otras mujeres (familiares), y

b) el tipo de ocupación, conforman el perfil preferencial en la selección de la emigrante. EI número de hijos también puede tener un efecto positivo sobre la selección en familias de "economías moderadamente pobres", a mayor número de hijos, mayores son las necesidades, otra «variable de presión a la emigración.

Las mujeres entrevistadas son de clases sociales de economías "moderadamente pobres" ${ }^{13}$. A la condición socioeconómica debemos incluir también el efecto positivo que pueda tener la habilidad académica y la condición socioeconómica de los padres. El perfil de las mujeres entrevistadas corresponde a:

a) Originarias de la isla de Luzón (sobre todo de las zonas más pobladas).

b) Nacidas entre el 1951 y el 1960.

c) De etnia tagolo e ilocana.

13. La categoría de teconomias moderadamente pobresp se desprende de la clasificación de la economía rutal filipina realizada por Pertierra, es decir, el grupo intetmedio entre los umuy pobres" y tos ricos" (propietarios, prestamistas, etc.). Vet Perrierra, R. (1988). Religion, Politics and Racionality in a Philippine Community. Manila: Ateneo de Manila University Press. 
d) De religión católica.

e) Mayoritariamente, solteras (pequeña diferencia con el número de casadas).

f) Tienen entre 3 y 6 hijos.

g) Con estudios universitarios finalizados. El $50 \%$ de las entrevistadas han acabado estudios superiores, lo que denota un at to nivel de estudios entre ellas ${ }^{14}$.

h) Poca o nula experiencia migratoria internacional.

En comparación con el perfil de las familiares-entrevistadas, las emigrantes a Cataluña responden a una emigración económica de una mujer joven (entre 21-35 años), soltera, católica y altamente cualificada, es, por tanto, un perfil muy similar en ambas situaciones.

5. Ante la falta de libre elección, el salario occidental es la única opción, y el trabajo doméstico la única oferta

Según las respuestas, el salario de una empleada doméstica en Cataluña multiplicaría por 23 el salario de una empleada doméstica en Filipinas, cosa que ilustra perfectamente las disparidades salariales. Este tipo de trabajo no se considera ni indigno ni vergonzoso $y$, lo que es más, trabajar y vivir en el mismo lugar - - la casa de los empleadores- es el trabajo más seguro para una mujer filipina. Aceptan el trabajo en Cataluña, la razón es la diferencia salarial. El que este trabajo en la emigración se perciba como positivo no implica una pérdida de status a los ojos de su comunidad. Pese a que esté bien visto que la mujer se marche al extranjero a trabajar en el servicio doméstico (muchas tienen estudios), no está siempre bien visto hacerlo en Filipinas, porque el servicio doméstico en Fillipinas además de ser pobre no tiene estudios.

No contamos con ningún caso de empleada doméstica en Filipinas. Curiosamente, muchas de las mujeres que emigran tienen trabajadoras en casa, pero no en las mismas condiciones que en el extranjero (horarios sin fijar, integración dentro de la familia, etc.). Lo más frecuente es que sean parientes: chicas jóvenes que necesitan salir de casa por razones de economía familiar, o para poder estudiar en el pueblo en el caso de que provengan de localidades alejadas de los principales núcleos de la provincia.

6. La elección del país comporta un análisis de la flexibilidad fronteriza, del mercado de trabajo y de la estereotipación de los estilos de vida de los países de destino

Dadas las circunstancias socioeconómicas del país de origen, la elección del pafs se entiende como una oportunidad que se le presenta a la persona, más

14. Normalmente, a más nivel educativo más información tienen sobre la vida en Catalufa y más conocimiento sobre los otros países. A pesar de todo, en algunos casos, el nivel de estudios no es tan criterio demasiado operativo, ya que incluso entre mujeres licenciadas encontramos una gran disparidad de niveles culturales. 
que como una elección premeditada del país de destino.

Según la situación socio-económica, se crea una escala de posibilidades de destino. Así, desde la perspectiva de una persona que vive en el campo, lo más barato será emigrar a Manila (puede ser menos fructifero); en segundo lugar, a Hong Kong y a Singapur; en tercer lugar, a Arabia Saudita; en cuarto lugar, a Europa, y en quinto lugar, a Norteamérica.

Lo más usual es que la apertura de las fronteras sea el primer requisito para realizar el proyecto emigratorio.

Existe un gran desconocimiento sobre el cierre fronterizo europeo. Las respuestas que muestran que conocen los hechos, justifican el cierre, por ejemplo, en base a las exigencias del proceso tecnológico y a la prioridad concedida a la mano de obra nacional. Otras entrevistadas creen que las puertas no están cerradas y saben que la emigración ilegal continua. Hay una gran reticencia a emigrar como «ilegal», a causa de las informaciones que reciben sobre deportaciones a través de los medios de comunicación.

Debido al desconocimiento que mostraron las entrevistadas acerca de la ley de extranjería, la pregunta tuvo que cambiarse y preguntar sobre la ley de inmigración española en un contexto general. Se manifiesta un gran desconocimiento, sin embargo, por otro lado, se maniffesta un gran conocimiento de la reunificación familiar y de la dureza de la ley (en general).

En muchas ocasiones se realiza un tipo de selección del pais de acuerdo con el criterio de aquel que ofrezca el salario más alto. (Según datos oficiales, España ofrece salarios medios, Canadá muy alros, y bajos Singapur y Kwait, POEA 1989.) Estos tipos de respuestas suelen dejar de lado las condiciones de trabajo, lo que evidencia el bajo grado de concienciación respecto a aspectos cruciales de la vida del emigrante en el país de destino (horarios, trato con los patrones, etc.).

La disparidad entre los estilos de vida - pobreza versus lujo- es la reproducción de la disparidad entre los salarios, por tanto, una de las causas clave de la emigración.

En algunas entrevistas, al comparar las dos sociedades y sus sectores más pobres, surge la idea de contraposición entre "la sociedad igualitaria" (la socialdemocracia española) y la usociedad feudal» desde las diferencias abismales entre ricos y pobres. No obstante, la percepción más extendida es la idea de que no existen pobres en Occidente, por tanto, no existe para ellas, el "Cuarto Mundo».

La inseguridad citudadana se percibe de una forma muy marcada en Filipinas, sobre todo desde el momento en que ven que aquellos que les deben proteger - la policía - son los que crean más inseguridad.

Si la idea que tienen de España se ha transmitido por los emigrantes, es normal que tal idea responda a un lado positivo que es reflejado por todos aquellos productos bonitos que trae el/la emigrante después de una larga estancia en el extranjero.

La idea de la España liberal y católica corresponde también con la idea que se tiene de Italia, lo que nos hace reflexionar sobre la similitud entre los modelos migratorios filipinos en España y en Italia. 
Por tanto, las semejanzas culturales, la libertad religiosa, el catolicismo y la menor incidencia en la explotación de las mujeres en comparación con otros países, hacen de España un lugar seleccionable en la emigración.

Más de una entrevistada menciona la elección de Estados Unidos como destino de la emigración. Este país ha representado tradicionalmente la aspiración máxima en el proyecto emigratorio de un filipino; también Canadá es un lugar muy apreciado.

Los pronósticos del gobierno filipino prevén nichos laborales en el mercado europeo y un cambio futuro en la orientación del mercado de mano de obra filipina hacia otros países como Taiwan.

Desde las entrevistas, cuando se habla de Europa los emigrantes tienden a tener una idea de proyecto de residencia permanente. Sobre Japón, una idea de deportaciones y entertainers, de Australia de mail order bride, de Hong Kong de chinos con tabúes religiosos y matrimoniales, de Arabia Saudí, una idea muy negativa ligada a un difícil asociacionismo, discriminación de la mujer, etc. en gran parte lo que corresponde con los reportajes sensacionalistas de los medios de comunicación.

\section{El concepto de integración se enraiza en una realidad interactiva} multiforme. A cada tipo de interacción entre sociedades le corresponde una integración diferente, lo cual se manifiesta en las diferentes imágenes y estereotipos de los países de destino

El concepto de integración parte de una interacción entre las dos partes, es decir, entre la sociedad de destino y las migrantes filipinas. Desde este punto se analizan las posibles condiciones a la adaptación desde la visión de las mujeres filipinas como emigrantes potenciales.

Desde esta perspectiva se incluye, por ejemplo, cómo aceptarán los autóctonos a los filipinos/as, la previsión de un conflicto - lingüístico-cultural-, o bien, la idea de armonía: a partir de los lazos históricos, el status social de la colonia filipina en los colectivos de los emigrantes, la aceptación de los matrimonios mixtos y la predisposición a aprender el catalán.

Se comprueba un desconocimiento absoluto de la lengua catalana, pero, por otra parte, una predisposición de las mujeres entrevistadas a querer aprender lenguas extranjeras, y en el caso del catalán lo harian porque representa una herramienta básica de comunicación entre los emigrantes y los autóctonos, aunque también se justifica el aprendizaje de la lengua desde la integración laboral. Este desconocimiento del catalán y de Cataluña puede deberse a la falta de incorporación de los rasgos culturales catalanes entre sus farniliares en la colonia filipina de Cataluña.

De la idea filipina pakikipagkapwa (preocupación humana e interacción como uno más con los demás) y bayaniban (una lucha común) se desprende el fuerte sentido de interacción en la colectividad. El asociacionismo se plasma primordialmente a través del barangay y a través de la acción católica, y escasamente a través de la política. Veamos algunos ejemplos: 
a) a través del asociacionismo católico carismático, el cual lucha en la comunidad rural por una acción social y por la competencia con otras religiones (mientras que en la emigración lucha por una acción social dirigida a las necesidades de los emigrantes y por el reforzamiento de la fe católica);

b) se da una correspondencia entre el hecho de ser fieles de la INK (Iglesia ni Kristo) y una falta de asociacionismo, quizás el activismo político del INK dé respuesta a las demandas asociativas;

c) por lo general, un nivel de asociacionismo político muy bajo, exceptuando tres casos: por un lado, las dos tendencias opuestas de la época de la dictadura - la lucha comunista en los años setenta y la de los jóvenes aliados al régimen - por otra, el activismo de los Born Again (la población no católica coincide comúnmente con los estratos más degradados socialmente).

Según lo expresado en las entrevistas, siempre se mantiene la religión en la emigración. La mayoria de las mujeres son católicas, aunque muchas tienen otras religiones y sectas. Algunas personas que habían sido catolicas anteriormente y que posteriormente han cambiado su religión, lo han hecho con la finalidad de buscar una respuesta más directa. En las entrevistas, las fieles de la INK nos muestran las hostilidades existentes entre ellas y los católicos en Barcelona.

Hay múltiples opiniones acerca de los cambios culturales de los filipinos. Por una parte, señalan que el filipino es muy adaptable a otras culturas, pero, por otra, como mantiene sus costumbres y su sentimiento nacionalista intensamente. Señalan que el emigrante cambia a menudo los elementos de apariencia externa e incorpora actitudes de "nuevos ricos".

En conjunto, consideran que la mentalidad filipina es conservadora; ésta se construye a partir de un rígido sistema moral basado en los valores católicos tradicionales y en un férreo sentido de la disciplina (los padres son muy estrictos para con sus hijos). En oposicion, el mundo extranjero se presenta como liberal (lo que puede ser peligroso: drogas, amor libre, etc., visión acompañada de un sentido diferente del tiempo libre). Defienden un tipo de educación igualitaria entre niños y niñas, no obstante, desde el punto de vista de las entrevistadas, este tipo de educación no debe olvidar las bases de una férrea disciplina y una moral tradicional.

Existe una gran diversidad étnica y lingüística, sin embargo no está totalmente construida en base a una diversidad cultural desde el momento en que sólo el inglés y el tagalo son las lenguas oficiales, y desde el momento en que los tagalos están más representados en las esferas de la toma de decisiones del país.

La mayoría de las mujeres --a pesar de su nivel de inglés - no comprenden el significado de la palabra racismo. Cuando lo comprenden a menudo ignoran o rechazan la existencia del racismo en Filipinas.

No se menciona el racismo de los mestizos filipinos ni el sexismo de las grandes redes de prostitución montadas alrededor del cliente occidental, sea éste militar o turista. 
Los únicos casos que podemos incluir es el resentimiento que muestran hacia los chinos (debido a stu fuerte representación empresarial en el país y por sus reglas de homogeneidad cultural), un tipo de discriminacion no demasiado bien definida hacia los aitas ("negros", adjetivados en ciertas ocasiones como atrasados o como ignorantes), y un ambiente hostil entre cristianos y musulmanes.

Tienen una buena imagen de los espafioles, sblo en dos casos se habla de racismo en Cataluña, uno directo, a partir de una agresión a una trabajadora doméstica por parte de su patrona, y otro indirecto, en el que se comenta que a veces se mira a la trabajadora doméstica por encima del hombro.

Cuando hablan del racismo fuera de Filipinas, sienten que si bien ellos/as son amables y hospitalarios con los extranjeros, cuando ellos/as van a trabajar al exterior les tratan como seres inferiores. Se refieren sobre todo a Arabia Saudita.

Una opinión muy difundida es la de que los árabes tratan a los filipinos como animales: «explotan y violan a la mujer filipina». Tampoco están demasiado contentos sobre el trato que reciben de los chinos en Hong Kong. En contraposición, simpatizan con los americanos y con los españoles porque dicen que ellos les tratan como seres humanos.

Mientras que el racismo que manifiestan contra los árabes se basa en una idea de contraataque (como producto del resentimiento, y no porque no consideren a todos los individuos iguales), curiosamente, el racismo en Europa se basa en una idea de superioridad. 